\title{
The Pursuit of Sustainable ICT4D: Lessons from Timor-Leste
}

\author{
Abel da Silva \\ Research Center, National Parliament of Timor-Leste \\ abel.dasilva@alumni.anu.edu.au
}

\author{
Walter Fernandez \\ UNSW Sydney \\ w.fernandez@unsw.edu.au
}

\begin{abstract}
Information and communication technology for development (ICT4D) initiatives often result in abandonment following a successful technical implementation. This article contributes to the literature on the sustainability of ICT4D projects by proposing a substantive theory of Cultivating Sustainability. A qualitative study, based on three ICT4D implementation cases in a least developed country, served to explore the question of how the sustainability of ICT4D could be enhanced. This paper suggests that sustainability needs to be cultivated proactively and continuously, from project initiation to benefit realization. The article indicates specific strategies that can help least developed countries achieving the long-lasting benefits donors and recipients anticipated.
\end{abstract}

\section{Introduction}

According to Braa, Monteiro and Sahay [12 p.359], 'the lack of sustainability of working information systems [IS] in developing countries is striking' and has caused these countries to suffer direct and indirect costs such as financial, opportunity, political and beneficiary costs, as well as discouraging the governments from implementing similar initiatives in the future [37].

The failure rate in ICT4D projects is alarmingly high. In the government sector alone, studies have reported a failure rate of up to 85 percent [37], a rate that appears to be resilient. The World Bank's survey of around 1,300 projects approved from 2003-2010 found that less than 60 percent of the ICT4D projects supporting the delivery of government services to the public have achieved or were expected to achieve their intended results and that 70 percent of these projects also experienced cancellation or delay [41]. Among the types of failure, sustainability failure is an insidious kind. It occurs when systems are abandoned after their initial successful implementation [2, 36, 80], thus wasting human and financial capital as well as not delivering the promised benefits.

The high failure rate has a high cost in financial and human development terms. Since the 1980s, the World Bank has invested around US\$2.2 billion to finance 87 financial MIS projects in 51 developing countries [22], only a few of these systems will be sustainable beyond donor support and suffer a failure rate of approximately 80 percent [24]. While donors recognize and fund the strategic deployment of ICT for development [63], these systems often become merely unsustainable [6].

The study we report here provides a theoretical explanation [35] suggesting key processes and strategies geared to achieve sustainable ICT4D. To that end, we studied project implementation processes taking into account the beneficiary's (or host) perspective. The substantive theory emerged from interpreting data during a two-year exploration of three significant ICT4D projects in Timor-Leste.

The next two sections provide a brief background and describe our research methodology before moving to present the observed patterns contributing to achieving sustainability, in section four, and concluding the article.

\section{Background: sustainable information systems in ICT4D initiatives}

The implementation of information and communication technologies for development (ICT4D) projects in less-developed countries (LDCs) are both critical to their development and prone to failure [16, 38]. These projects often face formidable difficulties in sustaining their mission [20]. They suffer from a lack of resources and diminished political commitment [2] and thus are especially prone to sustainability failure.

Given the importance of sustainability in ICT4D research, the phenomena needed multiple angles of study. Some studies focused on standardization of data/information formats [42], application of a 'flexible standard strategy' for technology development in a complex setting [11], and development of reliable 
infrastructure [44]. Adding to these technical aspects of sustainability the IS literature also discussed ways to establish 'green data centers' locally in LDCs using energy-efficient technologies [4] and the use of recycled computers and training of local actors to manage and maintain the IT resources [73].

Sustainability also has political, institutional, and economic aspects. Strong leadership can be critical to guarantee successful implementation and sustainability [45] and by resolving the challenges of bringing different institutions together [43] and achieving economic and financial gains through increased efficiency [46] and subsidies for the user [9].

Moreover, a sustainable ICT4D initiative needs to focus on achieving sustainability from an end-user viewpoint. For example, through continuously addressing end-users' changing needs [5], building trust and cooperation with other social actors $[14,51]$, and the use of mobile platforms to consolidate ICT4D participations from the marginalized groups in the society, user involvement, increased ownership and social recognition at the local level [13].

More recently, we have calls to rethink suitability through a user-driven perspective for development [61]. Because typical ICT4D projects are often deployed in phases such as initiation, implementation, and post-implementation [57], it is necessary to understand how sustainability can be built across these phases. For example, the implementation phase typically involves critical decisions about selection of technology, its procurement and installation, and the assimilation, use, and adaption of the technology [3]. Since these phases involve local and foreign actors with different cultures, agendas, and interests $[17,39$, $60,78]$, we argue that we need to observe the dynamics of evolution in real-life ICT4D projects.

All the mentioned aspects are essential contributors to alleviate LDCs' difficulties in implementing and maintaining ICT4D [60]. Hence, continuous calls have been made for further research to improve our understanding of the processes of delivering sustainable ICT4D after the donors' investment [38, $61,64,80]$. These calls for process-focused sociotechnical research are congruent with the nature of projects involving heterogeneous actors from competing interests and backgrounds. These projects are affected by national agenda and international politics $[17,18]$, contesting rationalities and diverse cultures [79]. Importantly, these projects require changes in government institutions' culture and practice [17]. Thus presenting an overlap of technological and social elements in complex contexts in which "the designers play a limited yet consequential role" [39 p.900].
Also, adopting a system is often a multi-party decision negotiated by several influential stakeholders. While the IS literature has for long observed causes of failure [25], it seems that the risk of influential stakeholders' resistance has been understudied [76].

The mentioned background indicated the need to explore how the local implementers of donororiginated systems could enact processes aimed at enhancing the sustainability outcomes of their projects. We decided to study the phenomenon in context and longitudinally [57]. We aimed to derive a substantive theory [71] from explaining and informing [35] the under-investigated processes leading to project delivery and system sustainability.

\section{Research methodology}

Our objective in this study was to develop a process theory to conceptualize process as a sequence of events and phases [74] to explain and suggest a pattern of possibilities [35]. We adopted a combination of grounded theory methodology (GTM) $[30,31,33]$ and case study method [26, 27]. In our approach, we followed an overarching GTM strategy based on data from case studies [as suggested by 28].

We aimed to produce rigorous research outcomes also relevant to practice $[8,66]$. To that effect, we followed a process of abduction from real-life cases $[19,65]$ to explain how actors resolve their main concerns in their substantive field [71, 72, 77]. The adopted methodology:

a) Allowed studying complex organizational phenomena $[48,50]$ to develop a theoretical account of the complex change process in ICT4D project implementations [1].

b) Allowed the dynamic evolution of the inquiry through a theoretical sampling strategy [31], which enabled the systematic progression of knowledge through constant data comparison [33].

c) Enabled the control of biases by comparing our memos against data collected from the field to verify its relevance, guarding us against preconceived ideas and bias [33, 70].

d) Enabled the understanding of the dynamics of complex ICT4D project implementation and, at the same time, to validate research findings [55].

e) Provided guidelines for collecting and analyzing data to build middle-range theory [15] that enabled seeking rigor and relevance [29].

f) Allowed the research team to capitalize on the significant GTM expertise of the second author, thus overcoming the typical difficulties faced by novice use of the method [71].

By situating our exploration in a least developed country, we aimed to identify understated assumptions 
emerging from studies based on developed countries [7]. Timor-Leste provided such context. Timor-Leste is a Southeast Asian nation and one of the least developed countries in the world [69]. As a new, poor but resource-rich country, Timor-Leste presented an exciting setting for both research and practice; the country was rapidly modernizing while its people continued to observe traditional practices very closely.

We investigated three major ICT4D projects in the public sector in Timor-Leste. The Alpha project in the finance sector, the Beta project in the justice sector, and the Delta project in the education sector (project names are pseudonyms). The first author, a native to Timor-Leste, studied for extended periods the project teams on location, and such daily contact helped to develop a high level of sensitivity to the observed practice. Table 1 lists the data collected.

Table 1: Data collection across cases.

\begin{tabular}{|l|c|c|c|}
\hline Data Collection activity & Alpha & Beta & Delta \\
\hline $\begin{array}{l}\text { First author's fieldwork } \\
\text { immersion (in-situ co-location). }\end{array}$ & $\begin{array}{l}\text { Three } \\
\text { months }\end{array}$ & $\begin{array}{l}\text { Four } \\
\text { months }\end{array}$ & $\begin{array}{l}\text { Two } \\
\text { months }\end{array}$ \\
\hline $\begin{array}{l}\text { Formal semi-structured } \\
\text { interviews of current/former } \\
\text { ministers or vice-ministers, } \\
\text { consultants, vendors, directors, } \\
\text { end-users. }\end{array}$ & 11 & 15 & 15 \\
\hline Average length of the interviews. & 1 hour & 40 min. & 30 min. \\
\hline $\begin{array}{l}\text { Formal observations of meetings } \\
\text { and training sessions. }\end{array}$ & 10 & 20 & 24 \\
\hline $\begin{array}{l}\text { Supporting documents, including } \\
\text { project plans, meeting minutes of } \\
\text { meetings, and training materials. }\end{array}$ & 40 & 95 & 82 \\
\hline $\begin{array}{l}\text { Transcriptions from interviews, } \\
\text { observations, and notes. }\end{array}$ & $\begin{array}{c}170 \\
\text { pages }\end{array}$ & $\begin{array}{c}116 \\
\text { pages }\end{array}$ & $\begin{array}{c}146 \\
\text { pages }\end{array}$ \\
\hline
\end{tabular}

We collected and analyzed data from formal semistructured interviews, observations of meetings and training sessions, informal conversations, and electronic correspondence with the actors. Additionally, project documents (such as meeting minutes, reports, project plans, and others) served to explore the findings further.

Data collection progressed in three waves, each case required six months of dedicated study, to elicite the first round of understanding. We then re-contacted each case to gather additional data as the theory development across cases progressed.

The co-location of the first author was central to "conducting real-time observations of the events and activities in strategy development while they occur in time, and without knowing a priori the outcomes of these events" [74 p.181]. Also, the rapport generated during the fieldwork immersions facilitated candid accounts, clarifications, and updates via emails.

The analysis of the three cases took two years, during which the first author was able to collect further evidence to compare and contrast data across cases and to observe the evolution of each case. Congruent with the type of process theory pursued, the unit of analysis was the conceptualized event $[47,74]$.

The data strategy of constant comparison across the different types of data allowed us to confirm, enrich or reject the emerging concepts [30], and at the same time, increased the internal validity of the research and its findings [52]. We transcribed and translated the interviews before using qualitative data analysis software (ATLAS.ti) to follow GTM's data analysis procedures [30, 31, 33].

To complement the analysis and reach consensus between the authors, we used mind-maps, diagrams, and walkthrough discussions. The frequent discussions of ideas were critical to generate intellectual stimuli throughout the interplay between data collection and analysis [72], and thus to theorize.

\section{Findings and discussion: cultivating sustainability process theory}

Our study allowed us to conceptualize a cultivating sustainability process that has three phases: system adoption, system implementation, and system outcomes. In each of these phases, sub-processes help achieve the phase objective. Our interpretation of the data indicates a progression of what we identified the main concerns about sustainability at each stage of the initiative (see Figure 1 and its subsequent description).

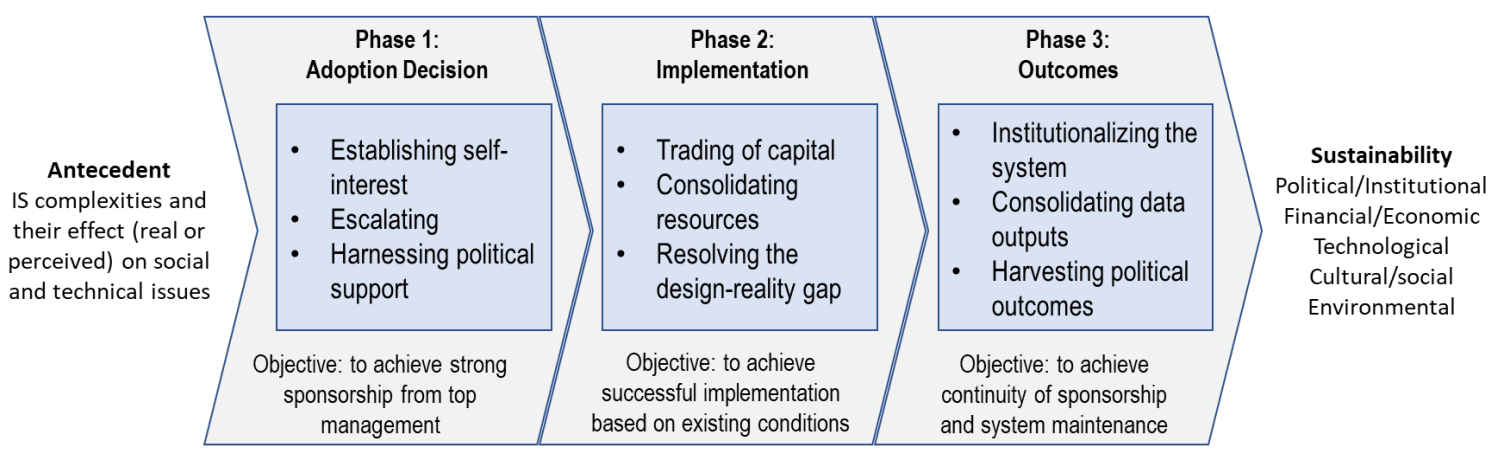

Figure 1: The Cultivating Sustainability Process Theory 


\subsection{Phase 1: system adoption decision}

Our data shows that ICT4D projects require a resolute effort to manage the highly probable event of resistance from top decision-makers during the system adoption decision phase. We observed that having the support of the host institution and the commitment of the donors was insufficient as a predictor of acceptance by the top management level affected by the change. Thus, a key concern is to achieve strong sponsorship from the host institution's relevant top-managers; in doing so, assuming unity of purpose among these stakeholders is risky and even foolish, as implementing information systems are likely to produce winners and losers [56].

We found three sub-processes as a critical to achieving strong sponsorship: establishing selfinterests, to convince the top-management about the technical and political benefits from system implementation; escalating, to deal with resistance from mid and high-level officials; and harnessing political support, to consolidate support from influential international actors in the host country. These subprocesses are synergistic, combining their outcomes enhance their effect on the project, as we discuss next.

4.1.1. Establishing self-interest. We observed actors engaging in the process of signaling self-interest motives to attain top management support. They aimed to increase top management's awareness of the potential technical and political benefits of the ICT4D project. Doing so was necessary as the top-managers were expected to act on their self-interest as well as on the interest of their institutions. The observed process is congruent with agency theory's assumptions that actors are boundedly self-interested; that is, norms and conventions bound their self-interest [10].

The establishing self-interest process deals on how to approach the top-management of the host institution to adopt the ICT solution and gain their support as champions of the project. This process requires a deep understanding of technical, economic, and political incentives that could be used to communicate with the relevant top-managers effectively. Communication tactics included showcasing a success story from relevant institutions that have implemented and successfully used similar systems.

It was also valuable to provide opportunities for topmanagers to declare their role in the initiative publicly - for example, by inviting the top-management to attend national and international forums that discuss the importance of system implementation in reforming the public sector. By publicly declaring support, or being perceived as supporters, of the initiative, topmanagers act as transformational leaders championing the project [75], and they become more committed to achieving the project objectives than having stated their support in private [40].

We also observed that engagement with the external forums increases the top-manager awareness of the potential self-benefit and political outcomes from implementing the system in their institution. In the Alpha project, the top-manager decided to implement ICT4D technology based on the realization of both technical and political potential benefits. Technically, the system would enable more efficient and transparent handling of the State budget. Politically, the system would introduce transparency and accountability to the public sector, thus bringing political outcomes in the form of recognition for the top management. Similarly, in the Beta project, the justice sector's top-management decided to implement the ICT4D technology based on the potential benefits from the achieving internal vertical transparency, where they will be able to oversee the performance of their subordinates, and the use of new statistical data, produced by the system, for improving the justice sector's decision-making processes.

In both Alpha and Beta projects, we observed that the increased awareness of the technical and political self-interest ramification of the ICT4D initiative resulted in stronger sponsorship by top management throughout the project implementation process.

4.1.2. Escalating attention. The Escalating Attention sub-process deals with ways to increase the external stakeholders' involvement and focus on the project and its implementation process. This sub-process works to achieve conflict resolution or to increase awareness. For example, bringing together the top-managements from relevant institutions in one forum to resolve issues regarding adoption decisions at the individual institution, or organizing discussion forums with external stakeholders, such as CSOs, international institutions and the public in general.

In the Beta project study, the project team overcame initial resistance from a powerful local actor by bringing the issue to a coordination forum in which topmanagement teams discussed critical issues in the justice sector. They also brought the issue to a few forums attended by national and international stakeholders to discuss the importance of implementing the system in the mentioned sector. These forums served three key goals: to deter officials with personal interests from undermining the system implementation process, to share information between the stakeholders involved, and to inform the public about the system implementation progress. These three elements encouraged the top-management to support the adoption of the technology. 
4.1.3. Harnessing political support. This sub-process deals with finding ways to harness political and diplomatic support from other influential international actors in the host country to support the ICT4D project implementation. By harnessing political support, the actors aimed at increasing the credibility of the project implementation in the eyes of the local topmanagement, creating further psychological pressure and further encouraging the top-management to adopt the technology. For example, the Beta project team approached ambassadors from key countries, such as the USA, Portugal, and Australia, to request financial and political support and to promote the initiative to the local top-management of the host institutions.

The top management's decision to adopt the system based on awareness of its potential technical and political benefits leads to strong sponsorship from the top management. Therefore, during the System Adoption Decision phase, it is critical to focus on maximizing strategies and actions leading to ensuring that potential champions are aware of how the project will benefit them and their constituents, and thus that the project receives a high level of attention and support. Harnessing political support also serves to counterbalance influential stakeholders whose interest may be negatively affected by the ICT4D initiative.

\subsection{Phase 2: system implementation}

The system implementation phase takes advantage of the strong sponsorship achieved in the first phase, and focuses on the successfully delivery of the ICT4D technology, in a manner that is congruent with the host institution's environment. To this aim, the project team enacts three subprocesses: trading of capital, consolidating resources, and resolving the design-reality gap sub-processes, as detailed next.

4.2.1. Trading of capital. We observed that it is necessary to manage the risk posed by the potentially unbalanced relationship between vendor and the hostclient $[23,34]$ by having a process conducive to the selection of the most appropriate vendor to deliver the ICT4D technology.

The trading of capital subprocess assumes that both the vendor and the host country are part of a bargaining process. Vendors are selected based on their possession of forms of capital, such as experience, expertise, international network, and their open-source business model. A potential vendor can also be approached using potential business opportunities and links with international institutions operating in the host country, and assessed on its capacity to transfers knowledge and human capital to the host-client.
A vendor possessing the above forms of capital will be able to deliver an ICT4D technology based on existing conditions of the host institution and prepare the local IT programming capacity to handle system enhancement. These steps will significantly reduce the cost of procurement and continued maintenance of the system. For example, in the Beta project, an experienced international vendor delivered the system. This vendor could deploy experts to develop a system driven by the end-users of the host institution and the ability to contribute actively in enhancing the local IT officials' programming skills. As a result, the locals can enhance the system independently from the vendor, and thus significantly reducing maintenance and licensing costs while enhancing the host institution's human capital.

4.2.2 Consolidating resources. This sub-process deals with ways to consolidate the project resources required for successful system implementation, use, and enhancement. This sub-process involves procurement and installation of ICT infrastructure, recruitment of human resources to support the system implementation and use, and raising end-users' awareness of the system and the potential changes involved.

In the Alpha project, the availability of ICT infrastructure, such as the network connectivity between government institutions, was crucial for system use and required implementing a network connecting each of the government buildings. The Alpha project also addressed the lack of capabilities of the city of civil servants by recruiting knowledgeable national adviserswho were local officials, not public servants, recruited with better salary packages.

Furthermore, the consolidation of resources implies an end-to-end view of project delivery, which must consider the need to educate end-users and mid-level managers, and also be educated by them. This bidirectional education must involve learning about the system and the potential changes in practices resulting from system implementation. In the Beta project, the project team dedicated significant time and effort to consult with the end-users and the mid-level managers about the new system.

4.2.3. Resolving the design-reality gap. A gap is highly likely to exist between the technological solution as designed and the reality of the host institution [37]. Thus, ICT4D projects must engage in the proactive consideration of this gap as an undefined barrier to project success, finding ways to deliver a technological innovation that is driven by the end-user needs and the host institution's existing conditions. In the Beta project, such process involved a slow process that included the following sequential steps: 
- During system design, several actions ensured the suitability and adaptability of the system to the local contexts, including mapping and socialization of existing manual process, the formalization of new processes, and, finally, the formal approval for system development from the institutional head.

- During the coding step, the vendor first developed prototypes to enhance consultations with end-users and the institution. The coding of the system started after the initial consultation period and proceeded as an iterative consultation process. Once the coding and testing phase concluded, the institutional head provided further approval for deployment.

- System deployment started with system installation and training of the end-users. The end-users were trained using printed screens and the actual online system. Also, training end-users to input legacy cases into the system reduced the impact of potential disruptions when using the electronic system.

Because end-users helped in designing the ICT4D technology according to their existing conditions, they experienced little difficulties in using the system. The Beta project also focused on developing the programming capacity of local IT officials to handle subsequent enhancement required by the end-users.

\subsection{Phase 3: harnessing system outcomes}

The third phase in the process model deals with creating the conditions for continued system use, which requires a focus on the technical and political outcomes of system implementation. The objectives of this phase are to secure the necessary enhancements and to increase top management's sponsorship; to that end, we identified the following three sub-processes.

4.3.1. Institutionalizing the system. After a successful system implementation phase, the system needs to become "the norm;" that is, it needs to be institutionalized $[54,56]$. We interpreted the subprocess of institutionalizing the ICT4D technology as an effort facilitated by the following actions:

- Ensuring an effective system hand-over that takes into account not only developing local capabilities to manage and maintain the system but also assisting local actors in developing an annual budget for system maintenance and enhancements, and working with the top-management to incorporate that budget in the overall budget plan to be submitted to the Parliament for approval.

- Promoting the organizational changes necessary to effectively incorporate the system into the everyday routine of the institution. For example, as part of the institutionalizing process, a new unit, the information management authority, was created with the role to provide advice to the top management on the issues related to system maintenance, training, and enhancement.

- Signaling the importance of the new information systems, the status of the IT departments in these government institutions were promoted to the higher level of the unit, and some IT officers with specialized skills were promoted as chiefs of departments.

Our observations add know-how to the assertion that an ICT4D technology becomes institutionalized when the new practices/procedures introduced by the system have been routinized and regarded as part of the host institution's daily life [62], and to the role of institutionalization processes in the sustainability of ICT4D initiatives [49].

4.3.2. Consolidating data outputs. Lack of accurate data to support the decision-making process in government institutions in LDCs is an everyday reality [67]. ICT4D initiatives can contribute to improving the accuracy and availability of data decision making, and thus helping to create conditions for benefits realization and continued system use. This consolidating data outputs sub-process contains the following:

- Publication of data outputs: openly share data produced by the system with the public. In the Alpha project, to achieve transparency and accountability in the handling of the State budget, data from the system was distributed through a budget transparency portal, which publishes how the state budget is spent by the respective government and state institutions [59].

- Sectoral data integration: government institutions in the same sector were also required to consolidate their data by integrating their data outputs at the sectoral level. In the Beta project, the project formed a dedicated unit to produce justice information generated from all the institutions in the sector.

- Cross-sectoral data linkages: for a better government-wide intervention, government institutions working across sectors are also required to share data between them electronically. In the Gamma project, government institutions delivering water and sanitation required data from the education sector. The data from the education ministry now helps the infrastructure ministry to identify the schools in need of their services.

4.3.3. Harvesting political outcomes. The harvesting political outcomes sub-process deals with ways to deliver political recognition from national and international institutions and forums to the top management's reform initiatives. 
For example, the Alpha project team used an international forum held in Timor-Leste to formally launch official web-portals, one of the outputs of the Alpha system. International figures, such as the former British Prime Minister Tony Blair, attended this prestigious event that heralded Timor-Leste's achievements in reforming the government sector, declaring the country 'a model of transparency' [58]. Also, the top management's effort in reforming government institutions received significant recognition when the UN Secretary-General appointed the relevant minister of the government institution implementing the Alpha project as a member of a UN high-level panel of 26 eminent people by [68].

We observed a similar international recognition to the top-management in the Beta project, where several top officials presented their efforts to deliver reforms at an international forum and received recognition from their counterparts in the Asia region. The essence of ICT4D implementation in government institutions is to bring reforms to these institutions. These reforms include changes in the way government conducts its business; for instance, it is often argued that government institutions need to function similarly to private sector institutions, where the citizen is the customer [21]. However, these changes are found to be problematic in the developing countries' context because of their traditional top-down government-tocitizen relationships [17]. Thus, the delivery of reforms demands a significant effort to encourage topmanagement to support those reforms.

Successful efforts to institutionalize the system combined with data output interdependencies between relevant government institutions, as well as the highprofile political recognitions enjoyed by the topmanagement from national and international forums helped to solidify top management's sponsorship. This outcome contributed to ensuring the continued allocation of crucial resources, continued system use, and subsequent enhancements within the host institution, and thus, its sustainability.

\section{Conclusion}

The discussed cultivating sustainability theory is a substantive theory [72]; as such, it has internal validity and works in the context from which it emerged [33]. Being a substantive theory also means that the theory was not meant to be not universally generalizable; instead, it aims at offering a significant level of knowledge transferability $[32,53]$.

The cultivating sustainability theory shows a threephase process aiming at achieving critical aspects of sustainability during the entire project implementation process, from the adoption decision to realizing the
ICT4D benefits. We grounded these phases on observed strategies to achieve strong sponsorship, a critical political aspect of sustainability. Further, the theory describes the effect of the host institution's existing conditions on the ICT4D initiative (i.e., economic, social and technical aspects of sustainability), and how the new system changes these conditions.

While the literature on the sustainability of ICT4D indicates individual aspects of sustainability, this paper contributes to research by proposing a theory that explains [35] how system sustainability outcomes can be a design decision in ICT4D projects - thus imbricating processes in a coherent theoretical model that includes critical strategies during the end-to-end project implementation and benefit realization process.

The knowledge advanced in our study also has a considerable potential to impact on practice. It can help to improve our understanding of how to deliver effective change in LDC using information and communication technologies, and help practitioners to reflect on the proposed theory and adopt appropriate sustainability strategies in their ICT4D initiatives.

\section{References}

[1] C. Avgerou, "The significance of context in information systems and organizational change", Information Systems Journal, 11 (2001), pp. 43-63.

[2] C. Avgerou, "Information Systems in Developing Countries: a Critical Research Review", Journal of Information Technology, 23 (2008), pp. 133.

[3] E. Baark, R. Heeks, "Donor-funded information technology transfer projects: evaluating the life-cycle approach in four Chinese science and technology projects", Information Technology for Development, 8 (1999), pp. 185-197.

[4] B. Baikie, L. Hosman, Green cloud computing in developing regions Moving data and processing closer to the end user, in: ITU Technical Symposium: Telecom World (ITU-WT) IEEE, Geneva, 2011, pp. 24-28.

[5] A. Bailey, "Issues Affecting the Social Sustainability of Telecentres in Developing Context: a Field Study of Sixteen Telecentres in Jamaica", The Electronic Journal on Information Systems in Developing Countries, 36 (2009), pp. 1-18.

[6] S. Bailur, "Using stakeholder theory to analyze telecenter projects", Information Technologies \& International Development, 3 (2006), pp. pp. 61-80.

[7] J.B. Barney, S. Zhang, "The future of Chinese management research: A theory of Chinese management versus a Chinese theory of management", 
Management and Organization Review, 5 (2009), pp. 15-28.

[8] I. Benbasat, R.W. Zmud, "Empirical Research in Information Systems: The Practice of Relevance", MIS Quarterly, 23 (1999), pp. 3-16.

[9] M.L. Best, D. Thakur, B. Kolko, "The Contribution of User-Based Subsidies to the Impact and Sustainability of Telecenters - The eCenter Project in Kyrgyzstan", Information Technologies \& International Development, 6 (2010), pp. 75-89.

[10] D.A. Bosse, R.A. Phillips, "Agency theory and bounded self-interest", Academy of Management Review, 41 (2016), pp. 276-297.

[11] J. Braa, O. Hanseth, A. Heywood, "Developing Health Information Systems in Developing Countries: The Flexible Standards Strategy", MIS Quarterly, 31 (2007), pp. 381-402.

[12] J. Braa, E. Monteiro, S. Sahay, "Networks of action: sustainable health information systems across developing countries", MIS Quarterly, (2004), pp. 337362 .

[13] J. Breytenbach, C. De Villiers, M. Jordaan, "Communities in control of their own integrated technology development", Information Technology for Development, 19 (2013), pp. 133-150.

[14] S. Cecchini, C. Scott, "Can information and communications technology applications contribute to poverty reduction? Lessons from rural India", Information Technology for Development, 10 (2003), pp. 73-84.

[15] K. Charmaz, Grounded Theory: Objectivist and Constructivist Methods, in: N.K. Denzin, Y.S. Lincoln (Eds.) Strategies of Qualitative Inquiry: Second Edition, Sage Publications, Thousand Oaks, CA, 2003.

[16] W. Chipidza, D. Leidner, "A review of the ICTenabled development literature: Towards a power parity theory of ICT4D", The Journal of Strategic Information Systems, 28 (2019), pp. 145-174.

[17] C. Ciborra, "Interpreting e-government and development: Efficiency, transparency or governance at a distance?", Information Technology \& People, 18 (2005), pp. 260-279.

[18] C. Ciborra, D.D. Navarra, "Good governance, development theory, and aid policy: Risks and challenges of e-government in Jordan", Information technology for development, 11 (2005), pp. 141-159.

[19] K.G. Corley, D.A. Gioia, "Building theory about theory building: what constitutes a theoretical contribution?", Academy of management review, 36 (2011), pp. 12-32.

[20] M.R. De Zoysa, N. Letch, "ICT4D Project Sustainability: An ANT-based Analysis", (2013), pp.

[21] Deloitte, At the dawn of e-Government: The Citizens as Customer, in, Deloitte-Research, New York, 2000.

[22] C. Dener, J. Watkins, W.L. Dorotinsky, Financial Management Information Systems: 25 Years of World Bank Experience on What Works and What Doesn't, The World Bank, 2011.

[23] G. Dhillon, R. Syed, F. de Sá-Soares, "Information security concerns in IT outsourcing: Identifying (in) congruence between clients and vendors", Information \& Management, 54 (2017), pp. 452-464.

[24] B. Dorotinsky, "Implementing financial management information system projects: The World Bank experience", Retrieved April, 6 (2003), pp. 2013.

[25] Y.K. Dwivedi, D. Wastell, S. Laumer, H.Z. Henriksen, M.D. Myers, D. Bunker, A. Elbanna, M. Ravishankar, S.C. Srivastava, "Research on information systems failures and successes: Status update and future directions", Information Systems Frontiers, 17 (2015), pp. 143-157.

[26] K.M. Eisenhardt, "Building Theories from Case Study Research", The Academy of Management Review, 14 (1989), pp. 532-550.

[27] K.M. Eisenhardt, M.E. Graebner, "Theory Building from Cases: Opportunities and Challenges", The Academy of Management Journal, 50 (2007), pp. 2532 .

[28] W. Fernandez, The grounded theory method and case study data in IS research: issues and design., in: D. Hart, S. Gregor (Eds.) Information systems foundations: Constructing and Criticising., ANU E-Press, Canberra, ACT, Australia, 2005, pp. 43-60.

[29] W. Fernández, H. Lehmann, "Achieving Rigour and Relevance in Information Systems Studies: Using grounded theory to investigate organizational change", The Grounded Theory Review, 5 (2005), pp. 79-107.

[30] B.G. Glaser, Theoretical Sensitivity: Advances in the methodology of grounded theory, Sociology Press, Mill Valley, Calif, 1978.

[31] B.G. Glaser, Doing Grounded Theory: Issues and Discussions, Sociology Press, Mill Valley, California, 1998.

[32] B.G. Glaser, A.L. Strauss, "Discovery of Substantive Theory: A Basic Strategy Underlying 
Qualitative Analysis", American Behavioural Scientist, 8 (1965), pp. 5-12.

[33] B.G. Glaser, A.L. Strauss, The discovery of grounded theory: strategies for qualitative research, Aldine Pub. Co., New York, 1967.

[34] S. Gopalakrishnan, H. Zhang, "Client dependence and vendor innovation: The moderating role of organizational culture", Industrial Marketing Management, 66 (2017), pp. 80-89.

[35] S. Gregor, "The Nature of Theory in Information Systems", MIS Quarterly, 30 (2006), pp. 611-642.

[36] R. Heeks, "Information Systems and Developing Countries: Failure, Success, and Local Improvisations", The Information Society, 18 (2002), pp. 101 - 112.

[37] R. Heeks, Most e-Government-for-Development Project Fails: How Can Risks be Reduced?, in: iGovernment, Institute for Development Policy and Management, Manchester, UK, 2003.

[38] R. Heeks, "Do information and communication technologies (ICTs) contribute to development?", Journal of International Development, 22 (2010), pp. 625-640.

[39] I. Holeman, M. Barrett, "Insights from an ICT4D initiative in Kenya's immunization program: designing for the emergence of sociomaterial practices", Journal of the Association for Information Systems, 18 (2017), pp. 900-930.

[40] J.R. Hollenbeck, C.R. Williams, H.J. Klein, "An empirical examination of the antecedents of commitment to difficult goals", Journal of Applied Psychology, 74 (1989), pp. 18.

[41] Independent Evaluation Group, Capturing Technology for Development: An Evaluation of World Bank Group Activities in Information and Communication Technologies, in: W.B. Group (Ed.), Independent Evaluation Group, The World Bank Group., Washington, DC, 2011.

[42] E. Jacucci, V. Shaw, J.r. Braa, "Standardization of health information systems in South Africa: The challenge of local sustainability", Information Technology for Development, 12 (2006), pp. 225 - 239.

[43] H. Kimaro, S. Sahay, "An Institutional Perpsepctive on the Process of Decentralization of Health Information Systems: A Case Study from Tanzania", Information Technologies for Development, 13 (2007), pp. 363-390.

[44] H.C. Kimaro, J.L. Nhampossa, "Analyzing the problem of unsustainable health information systems in less-developed economies: Case studies from Tanzania and Mozambique", Information Technology for Development, 11 (2005), pp. 273 - 298.

[45] S. Krishna, G. Walsham, "Implementing Public Information Systems in Developing Countries: Learning from a Success Story", Information Technology for Development, 11 (2005), pp. 123-140.

[46] R. Kumar, "eChoupal: A Study on the Financial Sustainability of Village Internet Centers in Rural Madhya Pradesh", Information Technologies \& International Development, 2 (2004), pp. 45-73.

[47] A.N.N. Langley, C. Smallman, H. Tsoukas, A.H. Van De Ven, "Process Studies of Change in Organization and Management: Unveiling temporality, activity and flow.", Academy of Management Journal, 56 (2013), pp. 1-13.

[48] K. Locke, Grounded Theory in Management Research, Sage Publications, 2001.

[49] S. Madon, N. Reinhard, D. Roode, G. Walsham, "Digital inclusion projects in developing countries: Processes of institutionalization", Information Technology for Development, 15 (2009), pp. 95 - 107.

[50] P.Y. Martin, B.A. Turner, "Grounded Theory and Organizational Research", The Journal of Applied Behavioral Science, 22 (1986), pp. 141-157.

[51] S. Masiero, "Financial vs Social Sustainability of Telecentres: Mutual Exclusion or Mutual Reinforcement?", The Electronic Journal on Information Systems in Developing Countries, 45 (2011), pp. 1-23.

[52] S. Mathison, "Why Triangulate?", Educational Researcher, 17 (1988), pp. 13-17.

[53] R.K. Merton, Social Theory and Social Structure, Revised edition ed., Free Press, Glencoe, IL, 1957.

[54] M. Mignerat, S. Rivard, Positioning the institutional perspective in information systems research, in: Formulating Research Methods for Information Systems, Springer, 2015, pp. 79-126.

[55] S. Nasirin, D.F. Birks, B. Jones, "Re-examining fundamental GIS implementation constructs through the grounded theory approach", Telematics and Informatics, 20 (2003), pp. 331-347.

[56] W.J. Orlikowski, D. Robey, "Information technology and the structuring of organizations", Information systems research, 2 (1991), pp. 143-169.

[57] C. Pade-Khene, B. Mallinson, D. Sewry, "Sustainable rural ICT project management practice for developing countries: investigating the Dwesa and 
RUMEP projects", Information Technology for Development, 17 (2011), pp. 187-212.

[58] RDTL, Beyond EITI: Timor-Leste a model of transparency, in, RDTL, Dili, 2011.

[59] RDTL, Press Release - Timor-Leste holds regional conference for International Extractive Transparency Initiative, "EITI and Beyond", in: Council-of-Ministers (Ed.), Government of Timor-Leste, Dili, 2011.

[60] S. Sahay, C. Avgerou, "Introducing the Special Issue on Information and Communication technologies in Developing Countries", The Information Society, 18 (2002), pp. 73-76.

[61] S. Sahay, A. Mukherjee, Self-Reinforcing Linkages Between Value and Local Ownership: Rethinking Sustainability of ICT4D Project, in: International Conference on Social Implications of Computers in Developing Countries, Springer, 2017, pp. 487-497.

[62] L. Silva, J. Backhouse, "The circuits-of-power framework for studying power in institutionalization of information systems", Journal of the Association for Information Systems, 4 (2003), pp. 294-336.

[63] L. Silva, R. Hirschheim, "Fighting against windmills: Strategic information systems and organizational deep structures", MIS Quarterly, 31 (2007), pp. 327-354.

[64] M.L. Smith, L. Elder, H. Emdon, "Open development: a new theory for ICT4D", Information Technologies \& International Development, 7 (2011), pp. pp. iii-ix.

[65] D.E. Stokes, Pasteur's quadrant: Basic science and technological innovation, Brookings Institution Press, 2011.

[66] D. Straub, S. Ang, "Editor's comments: Rigor and Relevance in IS Research: Redefining the Debate and a Call for Future Research", MIS Quarterly, 35 (2011), pp. iii-xi.

[67] UN, The Millennium Development Goals Report 2010, in, The United Nations, New York, 2010.

[68] UN, UN Secretary-General Appoints High-Level Panel on Post-2015 Development Agenda, in: U.D.o.P. Information (Ed.), 2012.

[69] United Nations, World Economic Situation and Prospects 2019, in, United Nations, New York, NY, USA, 2019.

[70] C. Urquhart, An encounter with grounded theory: Tackling the practical and philosophical issues, in: E.M.
Trauth (Ed.) Qualitative Research in IS: Issues and Trends, IGI Publishing, 2001, pp. 104-140.

[71] C. Urquhart, W. Fernandez, "Using grounded theory method in information systems: the researcher as blank slate and other myths", J Inf technol, 28 (2013), pp. 224-236.

[72] C. Urquhart, H. Lehmann, M.D. Myers, "Putting the 'theory' back into grounded theory: guidelines for grounded theory studies in information systems", Information Systems Journal, 20 (2010), pp. 357-381.

[73] U. Vallauri, "Beyond E-waste: Kenyan Creativity and Alternative Narratives in the Dialectic of End-ofLife", International Review of Information Ethics, 11 (2009), pp. 20-24.

[74] A.H. van de Ven, "Suggestions for Studying Strategy Process: A Research Note", Strategic Management Journal, 13 (1992), pp. 169-191.

[75] J. Van der Voet, B.S. Kuipers, S. Groeneveld, "Implementing Change in Public Organizations: The relationship between leadership and affective commitment to change in a public sector context", Public Management Review, 18 (2016), pp. 842-865.

[76] S.L. Vrhovec, T. Hovelja, D. Vavpotič, M. Krisper, "Diagnosing organizational risks in software projects: Stakeholder resistance", International journal of project management, 33 (2015), pp. 1262-1273.

[77] I. Walsh, J.A. Holton, L. Bailyn, W. Fernandez, N. Levina, B.G. Glaser, "What Grounded Theory Is... A Critically Reflective Conversation Among Scholars", Organizational Research Methods, 18 (2015), pp. 581599.

[78] G. Walsham, Interpreting Information Systems in Organizations, John Wiley \& Sons, Inc., 1993.

[79] G. Walsham, S. Sahay, "GIS for District -Level Administration in India: Problems and Opportunities", MIS Quarterly, 23 (1999), pp. 39-66.

[80] G. Walsham, S. Sahay, "Research on Information Systems in Developing Countries: Current Landscape and Future Prospects", Information Technology for Development, 12 (2006), pp. 7-24. 